\title{
Derivados de ubi e unde nas crônicas de Fernão Lopes ${ }^{1}$
}

\author{
Ubi and unde in Fernão Lopes' chronicles
}

\author{
Aléxia Teles Duchowny \\ Universidade Federal de Minas Gerais \\ Simone Fonseca Gomes ${ }^{2}$ \\ Universidade Federal de Minas Gerais
}

\section{Resumo}

Discussão dos derivados de ubi e unde latinos, tendo-se como corpus a Crônica de Dom Pedro e a Crônica de Dom Fernando, em português do século XV, da autoria de Fernão Lopes. Os itens resultantes da evolução de ubi e unde no português arcaico são descritos, e, em seguida, alguns de seus aspectos, em especial a abstratização, são analisados sob a perspectiva da gramaticalização. Os itens do português, basicamente espaciais, expandem sua abrangência coesiva, participando não só da coesão dentro da oração como fora dela e também entre conjunto de orações.

\section{Palavras-chave}

onde; português do século XV; conjunção; gramaticalização.

\section{Abstract}

Discussion of the derivatives of Latin $u b i$ and unde. The selected corpus is Crônica de Dom Pedro and Crônica de Dom Fernando, both written by Fernão Lopes, in XVth century Portuguese. The items $(d)$ onde and $(d) u$, resulting from the evolution of $u b i$ and unde in Old Portuguese, are described and then some of its as- 
pects, especially abstratization, are analyzed from the perspective of grammaticalization. (d)onde and (d)u, primarily spatial, expand their cohesive scope and participate not only in the cohesion in and between clauses, but also between groups of clauses.

\section{Keywords}

onde; Historical linguistics; conjunction; grammaticalization; XVth century Portuguese . 


\section{Introdução}

$\mathrm{P}$

ressupondo-se que "o estudo do desenvolvimento das línguas somente é possível porque as conservações do estado antigo e as inovações apresentam uma regularidade" (MEILLET, 1969, p. 26), o objetivo geral deste estudo é colaborar para uma gramática da língua portuguesa que inclua uma melhor compreensão dos seus mecanismos de mudança, dos processos diacrônicos e dos princípios gerais que interagem com esses processos linguísticos. Tendo em vista o objetivo geral, os derivados de ubi e unde no português do século XV, a partir das crônicas de Fernão Lopes, serão descritos e analisados.

Os derivados de ubi e unde no português, de uso frequente nas várias línguas românicas, revelam um funcionamento de alta complexidade, apresentando problemas categoriais e semânticos. Esses derivados aparecem, nos vários períodos da língua, com ou sem antecedente, precedidos de preposição ou de advérbio, podendo fazer parte também de expressões idiomáticas. Apresentamse como advérbio interrogativo, advérbio pronominal, pronome relativo, pronome adverbial e conjunção.

Um elemento tão complexo não tem sido ignorado pelos estudos linguísticos: vários autores já trataram especificamente do termo onde em português, com perspectivas teórico-metodológicas variadas: Araújo (2007), Bonfim (1993), Cambraia (1996), Coelho (2001), Kersch (1996), Marinho (2002), Oliveira (1997), Silva (2008), Souza (2003) e Souza (2007). Entretanto, até mesmo por essa variedade de abordagens, esse item gramatical demanda mais análises dos processos que ocorreram ao longo de seu percurso histórico. Colocou-se, assim, o seguinte problema para se dar partida à investigação: como se configura o qua- dro dos derivados de $u b i$ e unde latinos no português do século XV, época em que foram produzidos os textos de Fernão Lopes? 
No latim, de acordo com Gaffiot (1936), ubi é um advérbio relativo-interrogativo de lugar, empregado também como conjunção. Apresenta vários sentidos: no lugar em que, no momento em que, depois que, logo, etc. Unde também é um advérbio relativo-interrogativo de lugar que pode significar de que lugar, de que, do qual, de quem, dos quais, da parte do qual, daí.

No português, unde deu origem a onde, que pode apresentar variações gráficas (omde, honde, homde), e ubi origina $h u(u)$. Ambos podem ser antecedidos pela preposição de, gerando assim novas formas: d'hu e donde (d'onde, domde), de acordo com o corpus da pesquisa. Conforme Bonfim (1993), no século XIII, $u$ e onde se opunham semanticamente, sendo o primeiro de maior ocorrência. O valor semântico predominante de onde era a proveniência, enquanto $u$ tinha um valor de direção ou de localização estática, como fora no latim. Entretanto, nos séculos XIV e XV, além do uso predominante do onde, ocorre uma neutralização da oposição semântica dos elementos, passando as preposições a se tornarem as marcadoras de proveniência e direção. Os itens em questão sofrem um esvaziamento da ideia de proveniência e de direção. Assim, a substituição de $u$ por onde se deu no século XV e, já no século seguinte, João de Barros (1540) afirma que o uso do $u$ é um arcaísmo. Os autores, entretanto, não determinam a causa da preferência do onde em detrimento do $u$.

\section{Metodologia}

A gramaticalização, que servirá de guia para a análise em conjunto dos itens, é definida por Traugott e Heine (1991) como um processo tanto diacrônico quanto sincrônico de categorização e de codificação, no qual há uma tensão entre uma expressão lexical relativamente mais livre e uma codificação morfossintática menos livre. Há duas linhas principais de aproximação teórica ao fenômeno: para uma, o item lexical vai perdendo complexidade semântica, significância pragmática, liberdade sintática, substância fonética e se transforma em uma estrutura gramatical, que tende a se tornar mais e mais gramaticalizada; para outra, o foco está no discurso e na evolução da estrutura morfológica e sintática através de estratégias discursivas e o processo poderia ser representado da seguinte 
forma: discurso $\rightarrow$ sintaxe $\rightarrow$ morfologia $\rightarrow$ morfofonêmica $\rightarrow$ zero.

Uma característica presente no processo de gramaticalização muito discutida pelos estudiosos é a abstratização do input. Como se verificará em seguida, a partir dos dados do corpus, a noção primária de espaço será abstratizada, permitindo que itens antes espaciais possam se referir ao tempo e até a ideias. De fato, a própria etimologia da palavra espaço traz informações úteis para o entendimento da questão: ainda no latim, spatium pode ser traduzido como "expansão" e "distância" e em seguida "corrida", "período" e "medida de tempo" (RABANUS; KEHREIN; LAMELI, 2010). A tendência a obscurecer o espacial e favorecer a dimensão temporal não é, então, uma inovação do português em relação ao latim.

Para Immanuel Kant, o espaço é um modo de percepção, uma estrutura de toda experiência de objetos no mundo externo. Se o espaço não é algo em si, mas sim uma experiência humana, como todo modo de percepção ele poderá mudar e variar. No entanto, as diferenças entre espaço e tempo são substanciais: o primeiro é tridimensional, e o segundo é unidimensional; o movimento espacial é reversível, enquanto a passagem de tempo é irreversível; o espaço está relacionado a objetos, e o tempo, a eventos. Assim mesmo, em muitas línguas do mundo o primeiro é usado par expressar o segundo. Será essa expansão da noção de espaço que permitirá observarmos, nos dados, partículas primariamente espaciais capazes de fazer coesão entre grandes trechos do texto.

Os corpora do português do século XV foram a Crônica de Dom Fernando e a Crônica de Dom Pedro, de Fernão Lopes (DAVIES; FERREIRA, 2011). A escolha dos textos teve como critérios principais a datação e o tema. Crônicas, compostas de relatos, constituem um gênero com boas possibilidades de uso frequente de locativos, incluindo-se aí os derivados de ubi e unde. O fato de os textos estarem datados também aumenta a segurança da análise linguística.

Os itens analisados apareceram sob as seguintes formas, nos textos: onde, omde, bonde, bomde, hu, donde, domde, d'onde, d’hu; $u$ não foi encontrado. Por questões de economia, quando se estiver citando todo o conjunto acima, serão empregadas as formas (D)ONDE (que engloba onde, omde, honde, homde, donde, domdee d'onde) e (D)HU (que engloba bue d’hu) em caixa alta. 
Após a seleção dos trechos com uma das partículas e sua organização em listas, os aspectos analisados dessas partículas foram os seguintes: (a) classe gramatical, a partir de Cunha e Cintra (2001). Como se verá na análise dos dados, algumas partículas não se encaixam em nenhuma das classificações propostas pela gramática tradicional - as ambíguas e as intituladas partículas argumentativas; (b) significado da partícula no contexto em que se encontra; (c) categorias cognitivas da partícula, de acordo com Heine et al. (1991). Para esses autores, o processo de gramaticalização é estruturado metaforicamente, podendo ser descrito a partir de poucas categorias básicas que podem ser alinhadas da seguinte forma: pessoa $>$ objeto $>$ processo $>$ espaço $>$ tempo $>$ qualidade; (d) presença de preposição antecedendo a partícula. Verificou-se a presença/ausência de preposições antecedendo os itens estudados. Foram encontradas as preposições ataa, pera, contra, de e per. O donde foi analisado como preposição de + onde; (e) tipo de antecedente, no caso dos pronomes relativos. Os antecedentes puderam ser agrupados em grupos que apresentam um traço semântico mais acentuado do que os demais. Eles são: [+concreto] local físico com valor locativo intrínseco; [+tempo] metáfora espaço-temporal: ponto no tempo, sem valor locativo intrínseco; [+humano] ser animado; [-concreto] acontecimento, incluindo agrupamentos de pessoas, existentes no espaço físico/concreto.

\section{Apresentação dos dados}

Verificou-se a seguinte distribuição de (D)ONDE e (D)HU no corpus selecionado:

TABELA 1

Total de ocorrências de (D)ONDE e de (D)HU/divisão por classes gramaticais

\begin{tabular}{|c|c|c|c|c|c|c|}
\hline Classe gramatical & (D)ONDE & $\%$ & (D)HU & $\%$ & Total & $\%$ \\
\hline Pronome relativo & 219 & 75,8 & 69 & 70,6 & 288 & 74,6 \\
\hline Advérbio & 53 & 18 & 26 & 27,3 & 79 & 20,5 \\
\hline Partícula argumentativa & 12 & 4,2 & - & 0 & 12 & 3,1 \\
\hline Conjunção & 1 & 0,3 & 2 & 2,1 & 3 & 0,8 \\
\hline 'Ambíguo' & 4 & 1,7 & - & - & 4 & 1 \\
\hline Total & $\mathbf{2 8 9}$ & $\mathbf{1 0 0}$ & $\mathbf{9 7}$ & $\mathbf{1 0 0}$ & $\mathbf{3 8 6}$ & $\mathbf{1 0 0}$ \\
\hline
\end{tabular}


A frequência total de (D)ONDE é quase três vezes maior do que a de (D)HU (289/97). Entretanto, do ponto de vista morfossintático, a divisão interna de cada é bastante semelhante: a maioria é classificada como pronome relativo (75,8\%/70,6\%), vindo em seguida advérbio (18/27,3\%) e conjunção $(0,3 / 2,1 \%)$. Os itens ambíguos - que serão discutidos em breve - foram assim denominados porque não foi possível inseri-los com segurança em nenhuma das classificações ou porque podem, no mesmo contexto, aceitar duas interpretações. Alguns exemplos:

(1) leixou hi homëes de que sse fiava, e partio para Alcantara, hu rrecolheo todallas gentes porque avia enviado $\left(632 \mathrm{~F}^{3}\right)$ - Pronome relativo

(2) outras vezes convidava elrrei o conde e os outros capitaães, e ho hiia veer onde pousava el e a rrainha sua molher (2533F) - Advérbio

(3) Pois auemos de fazer meençom ao deante da guerra \&gramde desuairo que depois ouve antre o comde dom hemrrique \& elRej dom pedro seu Jrmaão. Neçessario he que comtemos primeiro como sse começou sua desaueemça\& de que guisa se el partio do Reino. E estoamte que emtremos aa guerra de castella com el Rei d'aragom. Em cuja aiuda el depois ueo Omde sabee que morto el Rei dom affonsso sobre o çerco de gibaltar. Que foi na era de mill \& trezentos \& oiteemta \& oito annos no mes de março. \& tomando todos por seu Rei o Jffamte dom pedro seu primogenito filho. Seemdo emtom em hidade de quimze annos \& sete meses \& estando na çidade de seuilha. Partirom do a-rreal com o corpo del Rei pera o uijnrë soterrar a castella mujtos dos senhores \& fidallgos que eram ali com elle. (7P) - Partícula argumentativa

(4) e (5) E aos que eram fidallgos e nom tiinham per hu aver boas armas e cavallos, a estes fazia elrrei mercee, per honde as podessem aver, e isso mesmo aaquelles que ssem sua culpa desfallecerom das conthias que aviam. (542F) - Conjunções

(6) e espedio-sse d'elrrei e foi-sse caminho de Sevilha: honde leixemos estar el rrei dom Pedro, e tornemos a contar d’elrrei dom Henrrique (525F) - Ambígua

\section{Os pronomes relativos}

Quando (D)ONDE e (D)HU são pronomes relativos, apresentam variados significados e são precedidos por antecedentes bastante diversos. Na tabela 2, classificaram-se esses antecedentes conforme os traços semânticos mais mar- 
cantes, e as ocorrências foram distribuídas em um contínuo que vai do menos abstrato para o mais abstrato. Decidiu-se não situar os antecedentes no contínuo de ca- tegorias cognitivas para não se agruparem antecedentes como retaguarda, batalha, conselho, dianteira, espessura, capitulo, armada, frota, feitos com antecedentes com maior grau de concretude, como cama, igreja, cidade, país, hgar, etc.

Em relação ao próprio pronome relativo, foi possível categorizá-lo de quatro formas: pessoa, objeto, espaço e tempo. A maioria, 97,2\%, das ocorrências se encaixa na categoria do espaço, que se encontra na seção da direita do contínuo de abstração sem, no entanto, estar no seu extremo. A categoria cognitiva mais abstrata, o tempo, tem apenas 1\% das ocorrências, assim como a menos abstrata, com apenas 0,4\%. Verifica-se que (D)ONDE e (D)HU, originalmente dêiticos de lugar, circunstanciam também tempo. A única ocorrência "inesperada" é a em que "aquelles" se refere a "homens", presentes em uma parte prévia do texto.

TABELA 2

O pronome relativo (D)ONDE e (D)HU - antecedentes e categorias cognitivas

\begin{tabular}{|c|c|c|c|c|c|c|}
\hline \multirow{3}{*}{$\begin{array}{c}\text { Tipo de } \\
\text { antecedente }\end{array}$} & \multicolumn{4}{|c|}{ CATEGORIAS COGNITIVAS } & \multirow[t]{3}{*}{$\%$} & \multirow[t]{2}{*}{$\mathbf{N}$. } \\
\hline & [-abstrato] & & & [+ abstrato] & & \\
\hline & $\begin{array}{l}\text { PESSOA } \\
\text { (do que) }\end{array}$ & $\begin{array}{l}\text { OBJETO } \\
\text { (lugar em } \\
\text { que, qual) }\end{array}$ & $\begin{array}{c}\text { ESPAÇO } \\
\text { (lugar em que, lugar para } \\
\text { que, lugar de que, que) }\end{array}$ & $\begin{array}{c}\text { TEMPO } \\
\text { (no momento em que } \\
\text { ou ponto futuro no } \\
\text { texto) }\end{array}$ & & \\
\hline [+ concreto] & - & 4 & 266 & - & 93,8 & 270 \\
\hline [- concreto] & - & - & 14 & - & 4,8 & 14 \\
\hline [+tempo] & - & - & - & 3 & 1,0 & 3 \\
\hline [+humano] & 1 & - & - & - & 0,4 & 1 \\
\hline$\%$ & 0,4 & 1,4 & 97,2 & 1,0 & 100 & \\
\hline Total & 1 & 4 & 280 & 3 & & 288 \\
\hline
\end{tabular}

Como se pode perceber, o valor mais usual dos antecedentes é [+concreto] (93,8\%), seguido de [-concreto] (4,8\%). No total de 270 ocorrências de (D)ONDE [+concreto], há apenas dois deles que indicam procedência; os outros casos são de 'lugar em que'. Exemplo:

(7) O bispo como ueo entrou na camara onde el Rei estaua. (143P)

Há poucos casos de (D)ONDE com um antecedente de lugar físico e que tem o significado diferente de 'lugar em qué. Encontrou-se também 
(D)ONDE com valor de 'no momento em que', no texto ou na linha do tempo (duas ocorrências). Exemplo:

(8) tanto que pôs em sua voontade de o matar, segundo acerca vereesadeante, honde falarmos da morte do conde (594F) - 'No momento em que'

Pode-se verificar, nessa ocorrência, que não é possível saber com certeza se o narrador está se referindo a um momento no futuro ou se faz menção a um ponto na narrativa ainda por vir. Essa ambiguidade, entretanto, não dificulta a compreensão por parte do leitor, porque as duas possibilidades identificam um ponto no futuro.

Há apenas duas ocorrências De (D)ONDE [- concreto] com o significado de 'da qual'. Exemplo:

(9) E estoassi feito foi elleuado pera a hordem d'auisdomde era meestre (13P) e uma única de (D)ONDE [+humano] com o significado de 'de quem':

(10) e isso meesmo dos bõos e grandes divedos que na vossa mercee tiinham aquelles d'onde eu descendo (10F)

(D)HU nunca tem como referente um antecedente [+humano], havendo apenas quatro ocorrências com antecedente [-concreto] e uma [+tempo]. Exemplo:

(11) logo a elrrei de Castella como tiinha todo firmado e o dia e o logarhusse aviam de fazer as vodas $(685 \mathrm{~F})$

O bu desse exemplo tem como antecedentes não só um ponto na linha do tempo ("dia"), como também "logar", [+concreto]. Já as duas únicas ocorrências de $d$ ‘ hu como pronome relativo indicam procedência, uma [+concreta] ("logar") e outra [-concreta] ("frota").

Em relação ao uso das preposições, pode-se fazer a seguinte distribuição dos mesmos dados: 
TABELA 3

Os pronomes relativos (D)ONDE e (D)HU - antecedentes e preposições

\begin{tabular}{|c|c|c|c|c|c|c|}
\hline Prepo- & \multicolumn{7}{|c|}{ Tipo de antecedente } \\
\cline { 2 - 8 } sições & {$[+$ concreto] } & [-concreto] & {$[+$ +tempo] } & {$[+$ humano] } & $\%$ & $\mathbf{N}$. \\
\hline$\varnothing$ & 238 & 19 & 3 & - & 90,3 & 260 \\
\hline$d e$ & 12 & 2 & - & 1 & 5,2 & 15 \\
\hline per & 13 & - & - & - & 4,5 & 13 \\
\hline Total & $\mathbf{2 6 3}$ & $\mathbf{2 1}$ & $\mathbf{3}$ & $\mathbf{1}$ & $\mathbf{1 0 0}$ & $\mathbf{2 8 8}$ \\
\hline
\end{tabular}

Em geral, (D)ONDE e (D)HU não são antecedidos por preposição. As 13 ocorrências de donde foram inseridas na coluna da preposição de, e seu valor mais comum é o de procedência (9 ocorrências). Entretanto, duas dessas treze ocorrências indicam 'lugar em que', e não 'lugar de que', e duas têm a ideia de posse.

Quando antecedido por per, o antecedente de bu é sempre [+concreto] e a preposição remete à ideia de passagem, "através de". Ao compararmos (D)ONDE e (D)HU, em relação aos pronomes relativos, verifica-se uma semelhança muito grande dos tipos de antecedentes e suas frequências, havendo apenas a exceção de uma única ocorrência [+humano] com (D)ONDE.

Quanto aos significados, 'lugar em que', ' lugar de que' e 'no momento em que' são comuns a ambos, enquanto há 'que' apenas com (D)HU (7,1\%), e 'lugar a que' (0,5\%), 'pelo qual' (0,9\%), 'de quem' (0,9\%) e 'que' (2,3\%) apenas com (D)ONDE.

As preposições que antecedem os itens em questão são as mesmas, per e de, mas há diferença na frequência. (D)HU, se antecedido por preposição, tem maior frequência de per (10\%) do que de de (2,9\%). Já (D)ONDE tem 5,9\% dos casos com de e 3,2\% com per.

\section{Os advérbios locativos e temporais}

Quando (D)ONDE e (D)HU são advérbios, encontramos a seguinte situação: 
TABELA 4

Os advérbios (D)ONDE e (D)HU - significados e preposições

\begin{tabular}{|c|c|c|c|c|c|c|c|c|}
\hline \multirow[t]{2}{*}{ Significado } & \multicolumn{5}{|c|}{ Preposição } & & $\%$ & N. \\
\hline & $\varnothing$ & de & per & pera & ataa & contra & & \\
\hline 'lugar em que' & 31 & 12 & 10 & 11 & 2 & 1 & 84,8 & 67 \\
\hline $\begin{array}{l}\text { 'lugar de que' } \\
\text { (procedência) }\end{array}$ & 1 & & - & - & - & - & 1,3 & 1 \\
\hline 'no momento em que' & 6 & - & - & - & - & - & 7,6 & 6 \\
\hline 'lugar a que' & 5 & - & - & - & - & - & 6,3 & 5 \\
\hline & & & & & & & 100 & \\
\hline Total & 43 & 12 & 10 & 11 & 2 & 1 & & 79 \\
\hline
\end{tabular}

Na maioria das ocorrências, (D)ONDE como advérbio não é antecedida por preposição $(67,9 \%)$ e tem o sentido de 'lugar em que'. Exemplo:

(13) seu filho e companha e cousas suas se fosse a Portugall pera seu marido ou onde lhe prouguesse (2485F)

Há poucos casos antecedidos por preposição (17 ocorrências). As oito ocorrências de donde $e^{4}$ advérbio, interpretadas como onde antecedido pela preposição de, têm a ideia de procedência. Exemplo:

(14) E pregumtoulhe domde partira \& que pousadas tijnha. (8P)

Há apenas um caso em que honde, sem preposição antecedendo-o, significa 'lugar de que'. Os casos em que (D)ONDE foi interpretado como 'no momento em que' foram cinco. Exemplo:

(15) hordenou em seuilha alli omde estaua de matar o meestre de samtiago dom fradarique seu Jrmaão. E mãdouho chamar onde uinha da guerra que dora tomar a uilla de Jumillha (149P)

O significado mais frequente de (D)HU advérbio é 'lugar em que' $(92,6 \%)$, e as demais ocorrências são de tempo e de direção. Exemplos:

(16) e entom desembargados [os falcoões] hiam-sse pera hu viviam, e viinham os falcoeiros e outros que de fazer aves tiinham cuidado. (624F) - 'Lugar em qué 
(17) JA teemdes ouuido cõpridamente hu fallamos da morte de dona enes (20P) - 'No momento em qué

(18) eu vou hu ella está, a fallar e fazer com ella o que compre a minha honrra (664F) 'Lugar a que'

Em relação ao uso das preposições, há mais ocorrências antecedidas pelas preposições per (sete ocorrências), pera (seis ocorrências), ataa (duas ocorrências) e de (quatro ocorrências) (73\%) do que sem preposição (27\%). As cinco ocorrências de $d^{\prime} h u$ foram inseridas na coluna da preposição de. Existe um caso interessante de d'bu antecedido da preposição pera. Nesse caso, pera acompanha o verbo anterior se tornarom, e d'bu significa 'lugar de onde'.

Vê-se que (D)ONDE e (D)HU advérbios são circunstanciais de lugar, principalmente, ou de tempo. Para Neves (2002, p. 251), lugar e tempo estão tão intrinsecamente implicados que um dêitico de lugar pode somar a essa indicação a indicação de tempo e vice-versa. Quanto a diferenças entre os dois itens, verifica-se maior variedade de significados do (D)ONDE. No caso das preposições, enquanto (D)ONDE apresenta uma ocorrência de contra antecedendo-o, (D)HU apresenta duas de ataa. A maior diferença está na frequência de ocorrências sem preposição, 73\% no caso de (D)HU e apenas 32,1\% no caso de (D)ONDE. Tem-se aqui um aspecto dos itens em questão que merecem um estudo à parte, que não será desenvolvido aqui. Quanto às categorias cognitivas, (D)HU apresentou apenas as de espaço e tempo, com maioria da primeira (94,3\%) sobre a segunda (5,7\%). Das espaciais, apenas uma ocorrência era [concreto]; as demais são [+ concreto].

\section{As conjunções}

O número de conjunções é muito restrito em relação ao todo, 1\% ((D)ONDE) e $2 \%$ ((D)HU). As ocorrências foram apenas três: (3) e (4) já citadas e (19) d'outra guisa nom me parece que he bem ordenardes per hu antre vós e elle aja guerra e discordia (641F).

Em (3), per hu é uma locução conjuntiva subordinativa de modo e, em 
(4) per bonde é locução conjuntiva subordinativa de finalidade. Já per bu, em (19), é uma locução conjuntiva de finalidade.

\section{As partículas argumentativas}

No corpus, foram encontrados doze casos de (D)ONDE chamados aqui de "partículas argumentativas". Nove ocorrências estão sob a forma da locução "onde sabee que", duas "onde aveo que" e uma "onde aqueeçeo que". O primeiro movimento foi inseri-las dentro da classe dos advérbios e entendê-las como proadvérbios, conforme Neves (2002): seriam advérbios fóricos, de natureza pronominal, que buscam ou recuperam uma informação, por remissão a um ponto do enunciado, ou à situação de enunciação (p. 251-2). Entretanto, essas partículas parecem fazer interface não somente com as classes dos advérbios e pronomes, mas também com a classe das conjunções. Exemplo:

(20) E el [GonçalloVaasquez] escusando-sse que nom sabia d’ello parte, e ella dizendo que era assi, leixarom aquello e fallarom em all. Honde sabee que este Gonçallo Vaasquez era segundo co-irmaão da rrainha dona lionor, e per ella fora feito e posto em grande estado (581F)

Mattos e Silva (2010) definiria essas doze ocorrências como "onde conclusivo" (p. 246), encontrado no século XIV. Para ela, não há referência a um antecedente, e o item expressa uma conclusão decorrente de argumentação desenvolvida no discurso. Seria equivalente aos atuais donde e logo. Segundo a autora, a marcante incidência do onde conclusivo decorre do discurso de tipo argumentativo de certas passagens de seu corpus.

Bonfim (1993) chamaria essa partícula argumentativa de "onde discursivo”, encontrado em seu corpus, do século XIII ao XV. Conforme seus dados, no Orto do esposo, do final do século XIV ou início do XV, o onde discursivo foi encontrado 278 vezes, enquanto todas as outras ocorrências somadas são apenas sete. Esse onde "estabelece uma ligação intra ou extra-frásica entre segmentos do texto, por necessidade argumentativa" (p. 99). Além do mais, "encabeça um segmento que remete anaforicamente ao que foi dito antes, não necessariamente ao 
que está presente no texto, mas, com frequência, à idéia transmitida." O onde discursivo alterna com a expressão e porém, usada nos mesmos contextos, nas mesmas circunstâncias.

Nas Crônicas, a partícula "onde sabee que" apresenta as seguintes características: (i) liga um conjunto de orações gramaticalmente independentes; (ii) ocupa uma posição fixa no início do conjunto de orações, tanto que, no corpus, a locução aparece sempre com letra maiúscula e após um ponto final. A pontuação é moderna e reflete a interpretação de um usuário do português atual, mas não deixa de ser uma pista importante; (iii) remete ao conjunto de orações precedentes; (iv) cria uma relação de explicação/argumentação, obrigando que o segundo segmento seja interpretado levando-se em conta o primeiro.

\section{As ambíguas}

(D)ONDE apresentou quatro casos em que o elemento em questão é ambíguo do ponto de vista morfossintático, permitindo, assim, ao menos duas interpretações por parte do leitor/ouvinte.

No exemplo (6), já citado, honde pode fazer o papel tanto de pronome relativo, que tem Sevilha como antecedente, quanto de advérbio, significando "aqui nesse ponto da história". Também poderia ser avaliado como uma conjunção, com o sentido de "assim". Em (20), a seguir, omde parece retomar todos os eventos relatados anteriormente, sendo uma partícula argumentativa, mas também pode ter o sentido da conjunçãopois:

(21) pois contra seu julgamento foi consemtidor em tamfea cousa como esta Omde assi aueo segundo dissemos que na morte de dona enes (28P)

Onde, a seguir, é uma conjunção do tipo assim, mas também uma partícula argumentativa:

(22) e eram os entendimentos dos homëes cheos de desvairados pensamentos. Onde em este logar departem alguuas estorias (2537F) 
Em (23), onde pode ser tanto a partícula argumentativa quanto a conjunção assim:

(23) E fazia [el Rei dom pedro] grandes Justiças em quaaes quer que dormiam com molheres casadas ou uirgeës \& Jsso meesmo com freiras dordem. Onde aqueeçeo que em sua casa auia huû corregedor da corte a que chamauã lourenço gomçalluez. Homem muj entendido \& bem rrazoado compridor de todallas cousas que lhe el Rej mandaua Fazer. (144P)

Nenhuma ocorrência de (D)HU, ao contrário, foi avaliada como ambígua.

\section{Discussão dos dados}

Expostos os dados, propõe-se distribuir os elementos encontrados no corpus no seguinte contínuo, em que os itens vão se tornando cada vez mais abstratos, da esquerda para a direita, em um processo de gramaticalização:

advérbio/pronome $\rightarrow$ conjunção $\rightarrow$ partícula argumentativa $\rightarrow$ ?[Ø]

[- abstrato]

[-gramaticalizado] [+abstrato]

[gramaticalizado]

Os usos de (D)ONDE e(D)HU assim constituídos convivem em um mesmo recorte de tempo, não só entre si, mas também com elementos concorrentes. Como se trata de um processo recorrente e interminável, é difícil, às vezes, identificar em qual fase estariam exatamente alguns dos elementos analisados, como é o caso das ambíguas e das partículas argumentativas. Esse tipo de processo de gramaticalização não é único; veja-se, por exemplo, os estudos de caso das conjunções assim em Gonçalves (2007) e logo em Longhin-Thomazi (2006). Não foi verificado se o estágio zero aparece efetivamente no corpus 5 .

Enquanto os pronomes e advérbios participam da coesão dentro da oração, 
as conjunções são responsáveis pela coesão entre as orações. As partículas argumentativas, por sua vez, colaboram para a coesão textual de uma forma mais ampla no português. Pode-se pensar, então, em uma gradação da abrangência coesiva dos elementos:

pronome e advérbio/coesão dentro da oração $\rightarrow$ conjunção/coesão entre orações $\rightarrow$ partícula argumentativa/coesão entre conjuntos de orações

Esse aumento da abrangência coesiva de itens primariamente espaciais é possível a partir da abstratização da noção espacial. Entretanto, é preciso lembrar que os pronomes relativos e os advérbios juntos são 96\% das ocorrências. Em outras palavras, $96 \%$ dos itens se encontram no lado esquerdo do contínuo de gramaticalização, próximas do extremo de [+ concreto] e do [-gramaticalizado]. Assim, podese concluir que as formas mais abstratas e muito gramaticalizadas de (D)ONDE e (D)HU têm baixa frequência no corpus selecionado do português do século XV. É muito provável que o gênero crônica propicie o uso de locativos concretos, ao contrário de textos mais dissertativos.

No século XV, (D)ONDE e (D)HU mudam de classe gramatical (advérbio/ pronome $>$ conjunção $>$ partícula argumentativa) e recebem propriedades de adjunção e de argumentação, participando da relação entre as sentenças. Também sofreram alteração semântica, perdendo seu sentido original e desenvolvendo novos sentidos (espaço > tempo). Não é surpreendente que o espaço esteja como o ponto de partida para a subjetificação e abstratização: sendo uma das experiências humanas mais básicas, a espacialidade se reflete também na linguagem humana. Como afirma Mendizábal (2011, p. 13) (em relação à linguagem oral, mas que poderia ser aplicado também à escrita, com exceção dos "gestos corporais"),

Cuando el ser humano se comunica oralmente con otros seres humanos se siente en la necesidad de orientar su discurso en el espacio y en el tiempo. Los gestos corporales acompañan a los elementos lingüísticos y le sirven para ordenar todo el mundo que le rodea tomando como eje de distribución el propio yo, el aquí y el ahora. (...) La contextualización en la que se enmarca el proceso de comunicación oral es una de las más fundamentales características 
pero tambíen es uno de los eslabones centrales del lenguaje, la percepción y la cognición.

Os derivados de $u b i$ e unde, originalmente indicadores de espaço físico, sofrem um processo de abstração tão intenso que têm condições de se tornar uma partícula argumentativa que pode fazer referência até mesmo a uma ideia não explicitada no texto e que demanda a inferência do leitor. Assim, o "onde sabee que" do português terá sempre mais de um sentido e variará conforme a leitura feita. Essa ambiguidade permite/favorece a gradação dos sentidos do (D)ONDE e a diferenciação no seu grau de abstratização.

Em outras palavras, a partícula argumentativa "onde sabee que" é prova da abstratização do significado de (D)ONDE, inicialmente espacial, em seguida temporal e, finalmente, argumentativo. Participaram desse processo gradual, conforme Traugott e König (1991), o mecanismo cognitivo da metáfora, que permitiu a expansão da partícula para além da esfera do concreto, e a metonímia, em que a reinterpretação contextual favorece a transição de um sentido a outro. A fonte da partícula argumentativa seria o uso mais referencial do (D)ONDE, um dêitico temporal que passa a ser empregado, em determinados contextos, como um item de coesão textual. Essa alteração e essa extensão do sentido do item apontam para a abstratização e a pragmatização, e o item passa a ser entendido de forma mais subjetiva, como uma partícula argumentativa.

\section{Considerações finais}

O estudo permite afirmar que, nas crônicas de Fernão Lopes, os pronomes relativos apresentam-se com antecedentes variados (apesar de apenas um [+humano]), sendo a maioria deles [+concreto]. Os significados são, também, bastante diversificados (ponto em que, ponto de que, lugar aque, pelo qual, que, do que, no momento em que), mas 'lugar em qué é o mais frequente. Per e de são as preposições que antecedem os itens analisados, mas a maioria das ocorrências não vem antecedida por elas. O significado dos advérbios, na maioria das ocorrências, é 'lugar em que'. As preposições antecedendo o advérbio são 
de, per, pera, contra e ataa, mas a maioria das ocorrências é sem preposição (54,4\%). A conjunção é sempre uma locução subordinativa, de finalidade ou de modo, iniciada pela preposição per. Já as partículas argumentativas são em número reduzido, mas indicam uma abstratização importante para o fenômeno da gramaticalização.

Os resultados dessa pesquisa histórica fornecem subsídios, principalmente, para os estudos da gramaticalização e da variação e mudança linguística. É preciso, entretanto, fazer-se um estudo diacrônico, levando-se em conta tanto um corpus anterior ao século XV quanto posterior a ele, para se entender melhor os mecanismos observados nessa análise. Por exemplo: o uso contemporâneo do aonde com o sentido de "lugar em que", condenado pela gramática tradicional, é um dos fenômenos que poderiam ser melhor esclarecidos pelo presente estudo. Para Cambraia (1996), a forma aonde seria uma variante protética da forma onde, após se verificar que aonde possui, desde o português arcaico, tanto o valor de "lugar em que" quanto o de "lugar a que". Os dados por ele analisados apontam que o aonde locativo que o aonde locativo só teria adquirido o sentido de "lugar a que" no século XVII. Nossos dados, do século XV, indicam que já nessa fase o português apresentava 6,3\% de ocorrências dos advérbios com o sentido de "lugar a que", apesar da ausência de aonde no nosso corpus. Exemplos:

(24) eu vou huella está. (664F)

(25) "E onde vos hiis, compadre?" (2549F)

Também se mostrou necessária a complementação desse estudo com outros sobre as partículas que coexistem com os derivados de $u b i$ e unde e que preenchem as mesmas classes gramaticais. A comparação dos dados do português com os dados das demais línguas românicas, verificando suas simetrias e assimetrias, também poderá apresentar esclarecimentos muito úteis aos estudos linguísticos em geral. 


\section{Referências}

ARAÚJO, L. E. S. Variação em locativos no português de Belo Horizonte: estudo sociolingüístico. 2007. 214 f. Dissertação (Mestrado em Estudos Linguísticos) Faculdade de Letras, UFMG, Belo Horizonte, 2007.

BARROS, J. de [1540]. Gramática da língua portuguesa com os mandamentos da Santa Madre Igreja. Rio de Janeiro: Fundação Biblioteca Nacional, 1995.

BONFIM, E. do R. M. Variação e mudança no português arcaico: o caso de $u$ e onde. Palavra, n.1, 1993. p. 96-119.

CAMBRAIA, C. N. Um estudo sobre a história do aonde na lingua portuguesa. 1996. 128 f. Dissertação (Mestrado em Estudos Linguísticos) - Faculdade de Letras, UFMG, Belo Horizonte, 1996.

COELHO, S. M. Uma análise funcional do onde no português contemporâneo: da sintaxe ao discurso. 2001. 123 f. Dissertação (Mestrado em Estudos Linguísticos) - PUCMG, Belo Horizonte, 2001.

CUNHA, C.; CINTRA, L. Nova gramática do português contemporâneo. Rio de Janeiro: Nova Fronteira, 2001.

DAVIES, M.; FERREIRA, M. O corpus do português. Disponível em: http://www. corpusdoportugues.org/. Acesso em: 28 fev. 2012.

DDGM. Dicionario de dicionarios do galego medieval. Santiago de Compostela: Universidade de Santiago de Compostela, 2012. Disponível em: <http://sli.uvigo. es/DDGM/>. Acesso em: 9 mar. 2012.

GAFFIOT, F. Dictionnaire abrégé latin-français illustré. Paris: Hachette, 1936.

GONÇALVES, S. C. L.; LIMA-HERNANDES, M. C.; CASSEB-GALVÃO, V. C. (orgs.). Introdução à gramaticalização. São Paulo: Parábola, 2007.

HEINE, B. et al.Grammaticalization: a Conceptual framework. Chicago: The University of Chicago, 1991.

KERSCH, D. A palavra ONDE no português do Brasil. 1996. 178 f. Dissertação (Mestrado em Estudos da Linguagem) - UFRS, Porto Alegre, 1996.

LONGUIN-THOMAZI, S. R. Gramaticalização de conjunções coordenativas: a história de uma conclusiva. Gragoatá, n. 21, 2006, p. 59-72.

MARINHO, J. H. C. O funcionamento discursivo do item onde: uma abordagem 
modular. 2002. 305 f. Tese (Doutorado em Linguística) - Faculdade de Letras, UFMG, Belo Horizonte, 2002.

MATTOS E SILVA, R. V. Estruturas trecentistas; elementos para uma gramática do português arcaico. Salvador: EDUFBA, 2010.

MEILLET, A. Introduction a l'étude comparative des langues indo-européenes. Forge Village: Universityof Alabama Press, 1969.

MENDIZÁBAL DE LA CRUZ, N. Preposiciones de tiempo y espacioenel discurso oral delespañol de Centroamérica. In: HERNÁNDEZ SOCAS, E.; SINNER, C.; WOTJAK, G. (eds.). Estudios de tiempo yespacioenla gramática espanõla. Frankfurt: Peter Lang, 2011. p. 13-28.

NEVES, M. H. de M. Os advérbios circunstanciais (de lugar e de tempo). In: ILARI, R. (org.) Gramática do português falado.v. 2. Campinas: Editora da Unicamp, 2002. p. 249-285.

OLIVEIRA, L. de A. B. A trajetória da gramaticalização do onde: uma abordagem funcionalista. 1997. 189 f. Dissertação (Mestrado) - UFRN, Natal, 1997. RABANUS, S.; KEHREIN, R.; LAMELI, A. Languageandspace. New York: Walter de Gruyter, 2010. v. 2.

SARAIVA, A. J. As crônicas de Fernão Lopes. Lisboa: Portuguália, 19--?.

SILVA, F. C. P. da. O percurso do item onde na perspectiva da gramaticalização. 2008.135 f. Dissertação (Mestrado em Estudos Linguísticos) - Faculdade de Letras, UFMG, Belo Horizonte, 2008.

SOUZA, E. H. P. M. de. A multifuncionalidade do onde na fala de Salvador. 2003. 284 f. Tese (Doutorado) - Instituto de Letras, UFBA, Salvador, 2003.

SOUZA, A. dos S. Tempo e espaço: a gramaticalização do item onde em textos religiosos (século XIV, XVI e XXI). 137 f. Dissertação (Mestrado em Letras, Estudos Linguísticos). Universidade Estadual de Maringá, Centro de Ciências Humanas, Letras e Artes, Maringá, 2007.

TRAUGOTT, E.; KÖNIG, E. The Semantics-Pragmatics of Grammaticalization Revisited. In: TRAUGOTT, E. C.; HEINE, B. Approaches to Grammaticalization. Amsterdam: John Benjamin, 1991.

TRAUGOTT, E. C.; HEINE, B. Approaches to Grammaticalization.Amsterdam: John Benjamin,1991. 
${ }^{1}$ Pesquisa realizada com o apoio da Pró-Reitoria de Pesquisa da Universidade Federal de Minas Gerais, Edital PRPq 08/2010

${ }^{2}$ Mestranda da Pós-graduação em Estudos Linguísticos da Fale-UFMG. A autora recebeu bolsa de iniciação científica da FAPEMIG, para a realização da pesquisa.

${ }^{3}$ Número da frase no corpus seguido de F, fazendo referência à Crônica de Fernando ou $\mathrm{P}$, referindo-se à Crônica de Dom Pedro.

${ }^{4}$ As oito ocorrências de donde, domde e d'onde advérbio foram incluídas na coluna da preposição "de" e na linha do significado "lugar em que", visto que o sentido de procedência está na preposição e para distinguir do caso em que onde, sem preposição, significa "lugar de que".

${ }^{5}$ Entretanto, ele pode existir potencialmente. Tome-se como exemplo as versões modernizadas de Saraiva (s/d). Em muitos casos, o autor apaga ou troca por outro item o derivado de unde no texto, na versão em português moderno, permitindo, assim mesmo, que o sentido original seja mantido: Onde sabee que $(2487 \mathrm{~F}) \rightarrow$ Sabei aqui que; Onde aqueeçeo que $(144 \mathrm{P}) \rightarrow \varnothing$ Aconteceu que; Omde assiaueo (28P) $\rightarrow \varnothing$ Assim aconteceu. 
